\title{
Nonspecific inflammation after new surgical procedures: The 'pouchitis' syndrome
}

\author{
SF PHILLIPS, MD
}

\begin{abstract}
The advent of a surgical alternative to conventional end ileostomy for patients requiring proctocolectomy for inflammatory bowel disease (IBD) offered new hope to many with intractable disease. The continent ileostomy (Kock pouch) and ileoanal pouch procedure have now been established, though they still are not standard approaches. Nonspecific inflammation ('pouchitis') is an important complication in 10 to $30 \%$ of such operations. The etiology is unknown, and the syndrome may even be heterogeneous; recurrent IBD, bacterial overgrowth and stasis are most often incriminated. Diarrhea, bleeding, malaise and even the extraintestinal features of IBD may occur. Though most patients respond to antibiotics or anti-inflammatory drugs, the pathogenesis of pouchitis poses major unanswered questions. This is perhaps the major challenge to IBD surgery at the present time. Can J Gastroenterol 1990;4(7):436438
\end{abstract}

Key Words: Ileo-anal anastomosis, Pouchitis, Surgical complication

\section{Inflammation non spécifique consécutive aux nouvelles interventions chirurgicales: le syndrome de la pouchite}

RESUME: L'avènement de nouvelles solutions chirurgicales remplaçant l'iléostomie terminale traditionnelle chez les patients porteurs des maladies inflammatoires d'intestin (MII) et requérant une proctocolectomie apporte un nouvel espoir dans de nombreux cas de maladie incurable. L'iléostomie continente (réservoir de Koch) et la procédure instituant un réservoir iléo-anal sont désormais des approches établies sinon standard. L'inflammation non spécifique appelée "pouchite" est une complication grave survenant dans 10 à $30 \%$ des cas. Ses causes sont inconnues et il se pourrait même que le syndrome soit hétérogène; récidives des MII, prolifération bactérienne et stase sont les plus souvent incriminées. Les diarrhées, hémorragies, malaises et manifestations extraintestinales propres aux MII peuvent survenir. Bien que la plupart des patients répondent aux antibiotiques et aux anti-inflammatoires, la pathogenèse de la pouchite soulève encore des questions importantes et non résolues. Cette affection constitue peut-être le défi majeur de la chirurgie MII actuelle.

\section{Mayo Clinic, Rochester, Minnesota, USA}

Correspondence and reprints: Dr SF Phillips, Gastroenterology Unit, Mayo Clinic, 200 Ist Street, Rochester, Minnesota 55905, USA. Telephone (507) 284-2511, Fax (507) 255-6318
A LTHOUGH THE OPERATION OF proctocolectomy and Brooke ileostomy restores normal health and may even be life saving in patients with severe inflammatory bowel disease (IBD), the emergence of less invasive ways of restoring continuity after proctocolectomy represents a major ad. vance. Indeed, the surgical milestones of the continent ileostomy and ileal pouch-anal anastomosis now offer the opportunity to justify proctocolectomy early and perhaps at more appropriate stages in the natural history of ulcerative colitis in particular patients. Another smaller group of patients for whom such procedures are employed regularly are those with familial polyposis coli.

Few benefits are realized, however, without a cost. In this instance it is the pathophysiological price of establishing a fecal reservoir in direct continuity with the small bowel. Longstanding clinical experience and basic physio. logical principles argue that the small bowel should be separated from the fecal flora; ileal pouch operations chal. lenge this concept (1). During the past decade the consequences of an ileal pouch on the nature of the intestinal flora and on mucosal histology have come to be appreciated (1-5). Al. though exact numbers of bacteria cul. 
tured vary among investigators, effluent from ileal pouches is much more fecal in nature than is the material that empties from conventional ileostomies (4-7). Total bacterial counts and the ratio of anaerobes to aerobes are more similar to stools than to the normal flora of ileostomies. This fecal milieu in ileal reservoirs changes the mucosal morphology towards one that is more colonic in appearance $(2,4,8-10)$. Villi are blunted or fused, and may even disappear completely, producing an appearance indistinguishable from colonic mucosa. Cell turnover is increased but cellular ultrastructure, including the brush border membrane, is often apparently normal. Mucus produced by pouch epithelia also takes on the histochemical properties of normal colonic mucus (9).

A major clinical expression of this unusual luminal environment is the syndrome of pouchitis. No aspect of these new surgical procedures is of more clinical importance but, unfortunately, pouchitis is still not well defined.

\section{CLINICAL FEATURES}

A wide range of quoted incidences suggests that the level of clinical suspicion and the diagnostic criteria for pouchitis vary greatly $(5,11,12)$. Indeed, in the majority of patients experiencing these problems, symptoms are intermittent and/or respond very well to therapy. However, in a minority, symptoms are severe and persistent enough even to lead to surgical removal of the pouch. Patients present with increased volumes of output, bleeding, discomfort in the pouch and general symptoms similar to those of the initial IBD. Fecal incontinence is also common. Classic extraintestinal manifestations in the skin and joints are occasionally seen (13).

Endoscopy shows the pouch mucosa to be reddened, swollen and often ulcerated. The mucosa is friable and bleeds readily from minor trauma during endoscopy; inflammatory changes are usually confined to the pouch but can also be seen in the adjacent ileum. Histologically, biopsies show a range of acute and chronic inflammatory changes depending on severity; fever, anemia and dehydration as a result of diarrhea may be variably present.

Exclusion of other possible etiologies is essential. Thus, the following points must be remembered: Patients with ileal pouches are not immune to superimposed specific enteric infections; stool culture and microscopy for parasites are appropriate. Recurrent Crohn's disease is always a major concern. The clinical features of the underlying IBD need to be reviewed carefully, including further pathological examination of the resected bowel. If one accepts that a small but definite proportion of colonic IBD falls into an 'unclassifiable' group, then one must anticipate that some patients with previously unrecognized Crohn's disease will present with pouchitis as the manifestation of recurrence. Surgical complications such as a strictured anastomosis with partial obstruction to outflow from the pouch need to be looked for carefully, and treated by dilation if present.

\section{TREATMENT}

If diarrhea alone is the major complaint, especially if endoscopic changes are not severe, treatment with simple antidiarrheal measures may be all that is required. For more severely symptomatic patients, a variety of empiric treatments have emerged. When the condition was first encountered in continent ileostomies (4), anecdotal evidence was that constant drainage would help. Such treatment was based on the assumption that stasis was an important predisposing factor. This is still usually done in patients with continent ileostomies; but those with pelvic pouches, unless there is significant stricturing at the anastomosis, usually have increased numbers of spontaneous evacuations. Metronidazole has been used often as a first line of treatment. The response to metronidazole or other broad-spectrum antibiotics can be quite dramatic. Some patients relapse after initial therapy with antibiotics, and require subsequent courses of treatment. In general, the antibacterial agents that have been most successful are those active against anaerobes.
When antibiotics are ineffective, treatment is with regimens that are effective in IBD. These include corticosteroid enemas, sulphasalazine, 5-aminosalicylic acid enemas and even systemic corticosteroids. The majority of patients who do not respond to antibiotics will improve on one of these programs. However, severe recurrent disease or major extraintestinal symptoms sometimes require that the pouch be removed.

\section{PATHOGENESIS, POSSIBLE ETIOLOGIES AND IMPLICATIONS}

Acute, nonspecific inflammation of ileal pouches certainly reflects the individual's propensity for IBD. Thus, pouchitis is much more common in patients for whom the pouch was constructed as treatment for IBD than it is in patients with polyposis coli. On the other hand, patients operated on for polyposis coli are not completely immune; perhaps multiple predisposing factors are needed for the development of pouchitis. However, the pathological features of pouchitis are nonspecific, and the acute inflammation seen in the pouches of IBD patients may be different from the changes seen (albeit, less frequently) in those of patients with polyposis coli. Indeed, pouchitis could well be the expression of a group of conditions, with different etiologies.

The histopathology of healthy and diseased pouches has only recently been examined systematically. The changes of chronic inflammation are usual, even in asymptomatic pouches; villus architecture is distorted and colonic metaplasia present in biopsies from most pouches. Thus, these changes must be considered natural sequelae of the altered anatomy. By analogy to experimental and clinical blind-loop syndrome (14), these histological changes have been attributed to bacterial overgrowth. Experimental pouches of ileum develop these changes without evidence of severe, acute inflammation (10).

Other possible etiologies are supported by few data. Some have suggested that pouchitis is due to ischemic 
changes, though this remains more an hypothesis than a well documented causative factor. Damage by bile acids or their bacterial metabolites is a possibility, since dihydroxy bile acids are intestinal secretagogues and cellular toxins $(1,15)$. In humans, the primary bile acid, chenodeoxycholic acid, and its secondary metabolite, deoxycholic acid, are active in this regard. Short chain fatty acids (SCFAs) have also been implicated in pouchitis, though how they should be incriminated is unclear. There is an increasing body of evidence that normal colonic mucosa

\section{REFERENCES}

1. Phillips SF. Biological effects of a reservoir at the end of the small bowel. World J Surg 1987;11:763-8.

2. Philipson B, Brandberg A, Jagenburg R, Kock N, Lager I, Ahren C. Mucosal morphology, bacteriology and absorption in intraabdominal ileostomy reservoir. Scand J Gastroenterol 1975;10:1-9.

3. Nicholls RJ, Belliveau P, Neill M, Wilks M, Tabaqchali S. Restorative proctocolectomy with ileal reservoir: A pathophysiological assessment. Gut 1981;22:462-8.

4. Kelly DG, Phillips SF, Kelly KA, Weinstein WM, Gilchrist MJ. Dysfunction of the continent ileostomy: Clinical features and bacteriology. Gut 1983;24:193-201.

5. O'Connell PR, Rankin DH, Weiland LH, Kelly KA. Enteric bacteriology, absorption, morphology and emptying after ileal pouch-anal anastomosis. $\mathrm{Br}$ ] Surg 1986;73:909-14.

6. Gorbach ST, Nakas L, Weinstein L. Studies of intestinal microflora. IV. The microflora of ileostomy effluent: A unique microbial ecology. Gastroenterology 1976;53:874-80.

7. Luukonen P, Valtonen V, Sivonen A, Sipponen P, Jarvinen H. Fecal bacteriology and reservoir after ileitis in uses SCFAs as a source of calories, and some have proposed that IBD can result when the colon is deprived of SCFAs $(16,17)$. The clearest clinical experiment to test this hypothesis was that of Harig et al (17) who proposed that 'diversion colitis' was such an example. It followed that patients with this condition should respond to enemas of SCFA, and they did. On the other hand, ileal pouches contain high concentrations of SCFAs (up to $100 \mathrm{mM}$ ), and a state of a deprivation seems unlikely. Indeed pouchitis has worsened or shown no predictable response to

patients operated on for ulcerative colitis. Dis Colon Rectum 1988;31:864-7.

8. Moskowitz RL, Shepherd NA, Nicholls RJ. An assessment of inflammation in the reservoir after restorative proctocolectomy with ileoanal ileal reservoir. Int J Colon Dis 1986;1:167. 74.

9. Shepherd HA, Jass JR, Duval I, Moskowitz RI, Nicholls RJ, Morson BC. Restorative proctocolectomy with ileal reservoir: Pathological and histochemical study of mucosal biopsy specimens. J Clin Pathol 1987;40:601-7.

10. Luukonen P, Jarvinen H, Lehtola A, Sipponen P. Mucosal alterations in pelvic ileal reservoirs. A histological and ultrastructural evaluation in an experimental model. Ann Chir Gynaecol 1988;77:91-6.

11. Fleshman JW, Cohen A, McLeod RS, Stem H, Blair J. The ileal reservoir and ileo-anal anastomosis procedure. Factors affecting technical and functional outcome. Dis Colon Rectum 1988;31:10-6.

12. Becker JM, Raymond JL. Mleal pouchanal anastomosis. A single surgeon's experience with 100 consecutive cases. Ann Surg 1986;204:375-83.

13. Lohmuller JI, Pemberton JH, Dozois
SCFA enemas (18). Pouchitis does not relate to the presence or absence of backwash ileitis at the time of proctocolectomy (19).

Thus, at this time, pouchitis remains just as great an enigma as the original IBD. It seems likely that pouchitis is trying to teach us something about IBD, but we are still not astute enough to decipher the message. Meanwhile, these patients must be treated as logically as possible and, at the same time, we must keep our minds open to what is still a 'hidden message'.

RR, Illstrup D. The relationship between pouchitis after ileal pouch-anal anastomosis and extra-intestinal manifestations of chronic ulcerative colitis. Ann Surg. (In press)

14. Donaldson RMJ, Toskes PP. The relations of enteric bacterial populations to gastrointestinal function and disease. In: Sleisenger MH, Fordtran JS, eds. Gastrointestinal Disease. Philadelphia: WB Saunders, 1983:44-53.

15. Nasmyth DG, Johnston D, Godwin PGR, Dixon MF, Smith A, Williams NS. Factors influencing bowel function after ileal pouch-anal anastomosis. Br J Surg 1986;73:469-73.

16. Roediger WEW. The colonic epithelium in ulcerative colitis - An energy deficiency disease? Lancet 1980;ii:712-5.

17. Harig JM, Soergel KH, Komorowski RA, Wood CM. Treatment of diversion colitis with short chain fatty acid irrigation. N Engl J Med 1989;320:23-8.

18. DeSilva HJ, Ireland A, Kettlewell M, Mortensen N, Jewell DP. Short-chain fatty acids irrigation in severe pouchitis. New Engl J Med 1989;321:1416-7. (Lett)

19. Gustavsson S, Weiland LH, Kelly KA. Relationship of backwash ileitis to ileal pouchitis after ileal pouch-anal anastomosis. Dis Colon Rectum 1987;30:25-8. 


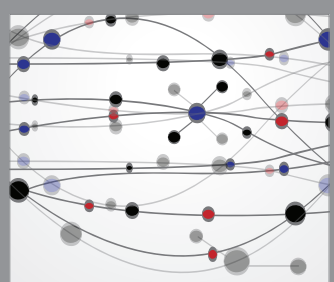

The Scientific World Journal
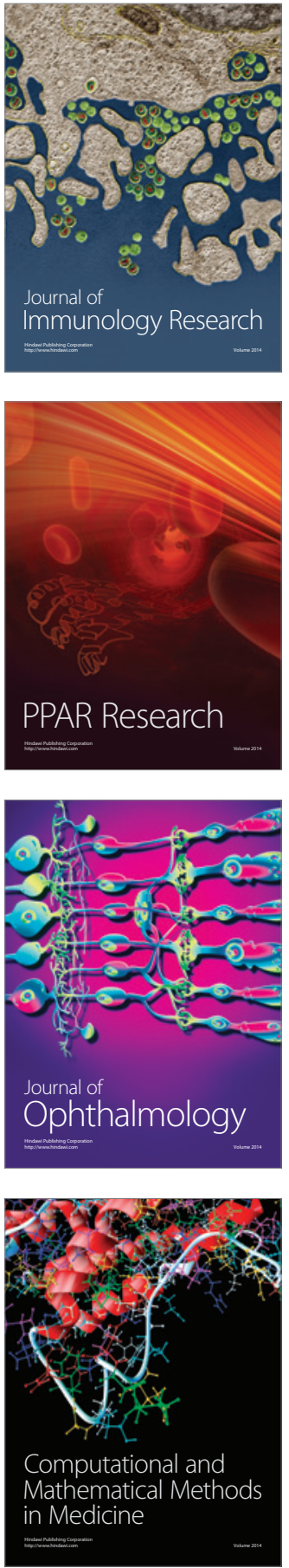

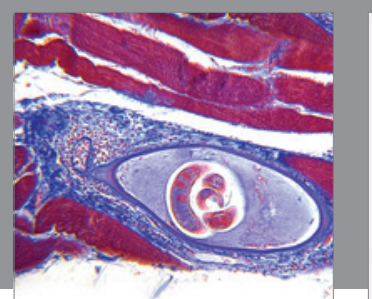

Gastroenterology Research and Practice

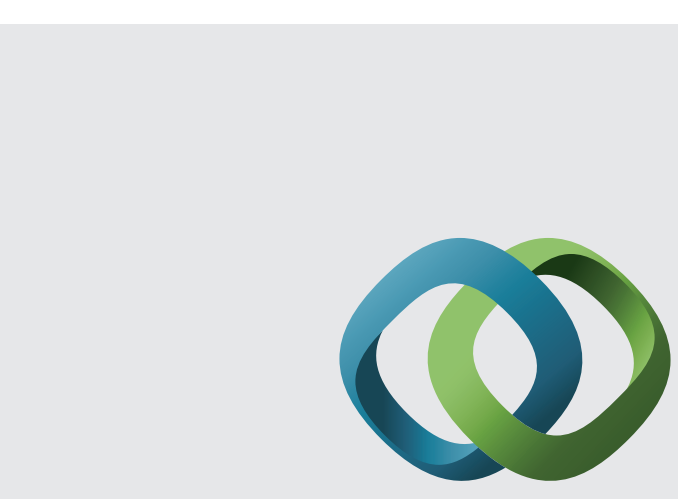

\section{Hindawi}

Submit your manuscripts at

http://www.hindawi.com
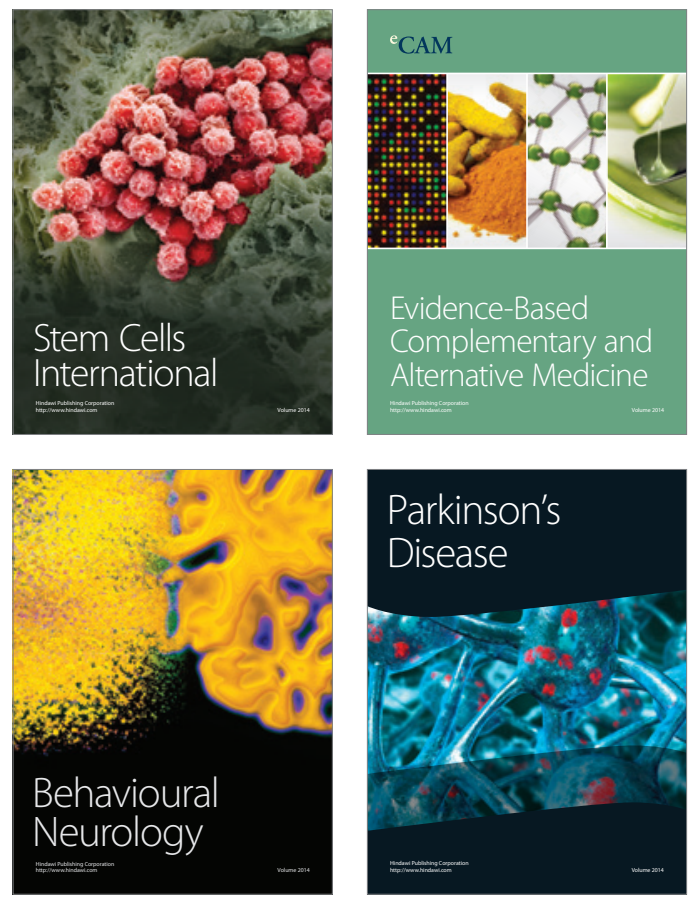
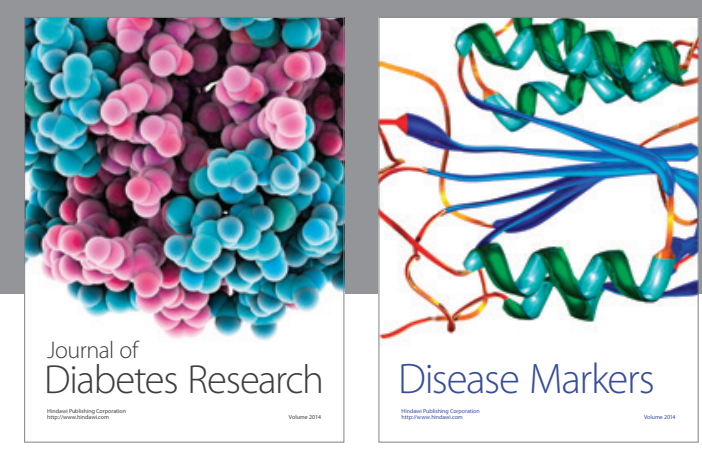

Disease Markers
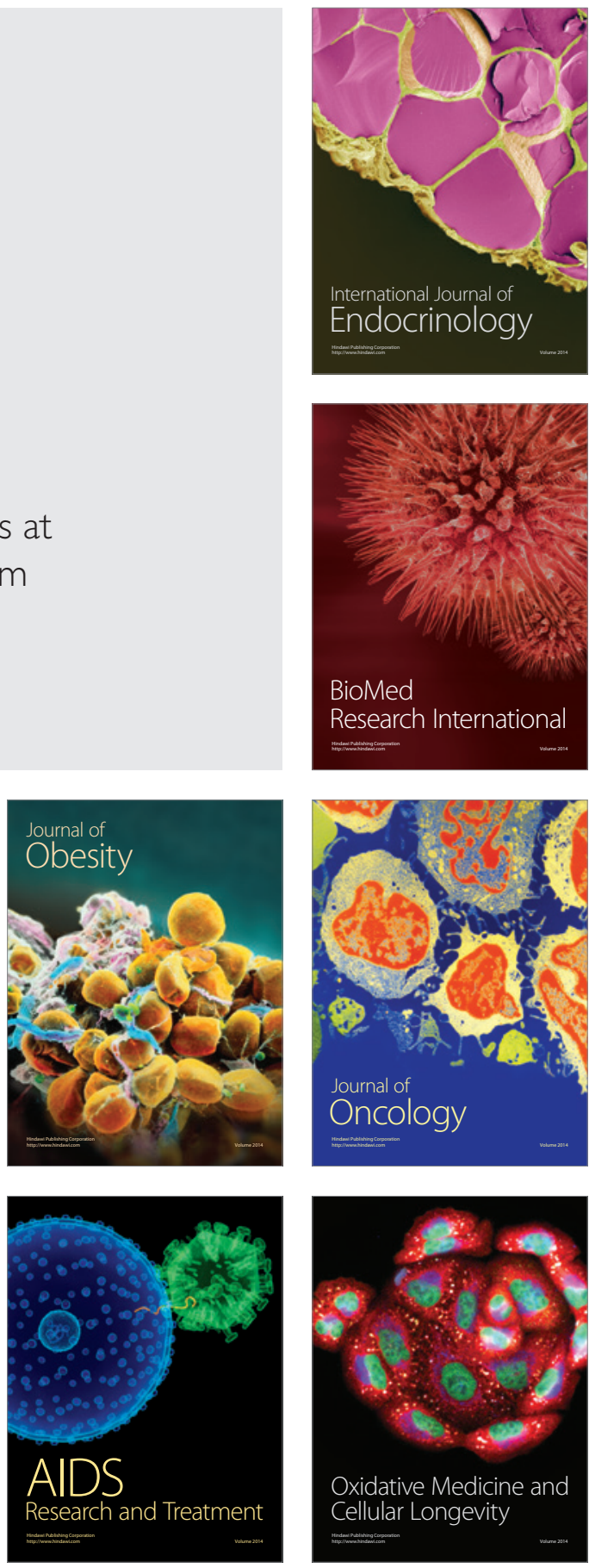